\title{
Germinação de sementes de maracujá-amarelo em extrato aquoso de tiririca e ácido giberélico
}

\author{
Germination of yellow passionfruit seeds in aqueous extract of purple nutsedge and gibberellic acid
}

\author{
Fabiola Villa*, Daiane Luckmann Balbinotti França, Angela Laufer Rech, Claudia Andrade Moura e \\ Felipe Fuchs
}

Recebido em 13/05/2015 / Aceito em 30/11/2015.

\section{RESUMO}

Alelopatia se refere à capacidade que determinada planta possui de interferir no metabolismo de outra, por meio de compostos químicos liberados no meio. A tiririca é um exemplo típico deste tipo de planta, possuindo elevada concentração de ácido indolbutírico, podendo agir na germinação e enraizamento de outras plantas. Diante do exposto, objetivou-se com o presente trabalho avaliar o efeito de extratos de bulbos e folhas de tiririca e ácido giberélico na germinação de sementes de maracujá-amarelo. Para a obtenção dos extratos aquosos de tiririca utilizaram-se bulbos e folhas na concentração de $1 \mathrm{~g} 10 \mathrm{~mL}^{-1}$ (p/v) $(1 \mathrm{~g}$ de matéria vegetal para $10 \mathrm{~mL}$ de água destilada), constituindo as soluções estoque. Foram utilizados extratos diluídos em cinco concentrações $(20,40$, 60,80 e 100\%) e cinco concentrações de ácido giberélico $\left(200,400,600,800\right.$ e $\left.1000 \mathrm{mg} \mathrm{L}^{-1} \mathrm{GA}_{3}\right)$. Como tratamento controle utilizou-se água destilada. O delineamento experimental foi inteiramente casualizado, apresentando 16 tratamentos, contendo cinco repetições, totalizando 80 unidades amostrais, contendo cada unidade dez sementes. Diariamente realizaram-se contagens do número de sementes germinadas para posterior cálculo de percentagem de germinação e Índice de Velocidade de Germinação. Sementes de maracujá-amarelo submetidas às concentrações de ácido giberélico tiveram sua germinação inibida, não sendo recomendado na germinação da espécie. Concentrações de extrato aquoso de folhas e bulbos de tiririca não influenciaram a germinação de sementes de maracujá-amarelo.

\section{ABSTRACT}

Allelopathy refers to the ability of certain plant has to interfere with the metabolism of other compounds by chemicals released into the environment. Cyperus rotundus is a typical example of such a plant, having a high IBA concentration and being able to influence and act on germination and rooting of the other plants. The aim of this study was to evaluate the effect of bulbs and leaves extracts of Cyperus rotundus and gibberellic acid on the yellow passion fruit germination cycle. To obtain the aqueous extract bulbs and leaves were used along with a concentration

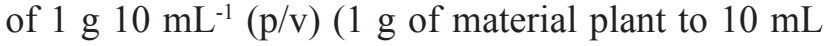
of distilled water), forming stock solutions. Extracts were diluted in five concentrations $(20,40,60,80$ and $100 \%$ ) and five concentrations of gibberellic acid $\left(200,400,600,800\right.$ and $\left.1000 \mathrm{mg} \mathrm{L}^{-1} \mathrm{GA}_{3}\right)$ were used. As a control treatment we used distilled water. The experimental design was completely randomized, with 16 treatments, five replicates, totaling 80 sampling units, each unit containing ten seeds. Daily counts were performed on the number of germinated seeds for subsequent calculation of germination percentage and germination speed index. Seeds of yellow passion fruit treated with concentrations of gibberellic acid had their germination inhibited and it is not recommended in the germination of the species. Concentrations of aqueous extract of leaves and sedge did not affect the germination of yellow passion fruit.

KEYWORDS: Passiflora edulis f. flavicarpa, Cyperus rotundus, plant extract, allelopathy.

PALAVRAS-CHAVE: Passiflora edulis f. flavicarpa, Cyperus rotundus, extrato vegetal, alelopatia.

Universidade Estadual do Oeste do Paraná, Marechal Cândido Rondon, PR, Brasil.

*Autor para correspondência $<$ fvilla2003@libero.it>. 


\section{INTRODUÇÃO}

O Brasil é o maior produtor mundial de maracujá com produção anual de 920 mil toneladas, em uma área de 62 mil hectares, sendo os estados da Bahia, Ceará, Espírito Santo, Sergipe, Pará, Minas Gerais e São Paulo os maiores produtores da fruta (IBGE 2012).

O maracujazeiro é originário da América Tropical, com mais de 150 espécies dentro da família Passifloraceae, utilizadas para consumo humano (SABIÃO et al. 2011). No Brasil as espécies de maracujazeiro mais cultivadas são o azedo ou amarelo (Passiflora edulis f. flavicarpa), roxo (Passiflora edulis) e doce (Passiflora alata) (LIMA et al. 2009). A espécie é propagada principalmente, dentre outras formas, via sexuada, por sementes, para implantação de pomares comerciais (WAGNER JUNIOR et al. 2006).

A Cyperus rotundus, usualmente nomeada como tiririca, é uma planta invasora muito conhecida. Originária da Índia encontra-se disseminada em mais de 92 países, sendo atualmente a planta invasora mais nociva do mundo (LORENZI 2000). É uma planta herbácea de ciclo perene, possuindo bulbos, rizomas e tubérculos subterrâneos. Seus órgãos subterrâneos podem produzir inibidores, como fenóis, flavononas, saponinas e taninos, capazes de interferir na germinação (CATUNDA et al. 2002) e crescimento de plântulas de várias espécies, fenômeno conhecido por alelopatia (BRITO \& SANTOS 2012). Suas folhas contêm alta concentração de auxina ou ácido indolbutírico (AIB), específica para a formação das raízes das plantas (LORENZI 2000).

Diversas pesquisas têm sido realizadas utilizando extratos de tiririca como forma alelopática em grandes culturas (CREMONEZ et al. 2013). Pesquisas na fruticultura ainda são escassas, principalmente em relação a eficácia do extrato na germinação e concentração ideal para determinada espécie que possa substituir o fitorregulador sintético.

Concentrações de extrato de bulbos de tiririca sobre picão-preto e alface foram estudadas, verificando que, as diluições do extrato estimularam a emergência das sementes de picão-preto e inibiram a emergência de sementes de alface (GUSMAN et al. 2011). SANTOS et al. (2013), estudando a germinação de sementes de maracujá-doce (Passiflora alata), submetidas a tempos de embebição e concentrações de ácido giberélico, afirmaram que, elevadas concentrações são benéficas para aumentar a velocidade de emergência das sementes, recomendando a utilização de $500 \mathrm{mg}$ $\mathrm{L}^{-1}$ de $\mathrm{GA}_{3}$.

Diante do exposto, objetivou-se com o presente trabalho avaliar o efeito de extratos de bulbos e folhas de tiririca (Cyperus rotundus) e ácido giberélico na germinação de sementes de maracujá-amarelo (Passiflora edulis f. flavicarpa), visando suprir sua dormência e irregularidade na germinação.

\section{MATERIAL E MÉTODOS}

Conduziu-se o experimento no Laboratório de Pós-Colheita da Universidade Estadual do Oeste do Paraná (Unioeste), Campus Marechal Cândido Rondon, entre maio-junho/2013.

Sementes de maracujazeiro-amarelo foram obtidas de frutos maduros, pré selecionados e oriundos de propriedade particular. Bulbos e as folhas de tiririca (Cyperus rotundus) foram utilizados no preparo dos extratos aquosos, sendo retirados de plantas coletadas na Fazenda Experimental da Unioeste, em área homogênea. Para a obtenção dos extratos aquosos foram utilizados bulbos e folhas na concentração de $1 \mathrm{~g} 10 \mathrm{~mL}^{-1}(\mathrm{p} / \mathrm{v})$ (1 $\mathrm{g}$ de bulbos e folhas de tiririca para $10 \mathrm{~mL}$ de água destilada), constituindo as soluções estoque. Estes foram primeiramente limpos, lavados em água corrente, previamente secos e em seguida triturados em liquidificador com água destilada. A mistura foi deixada em repouso por 48 horas em geladeira, para posterior filtragem.

Após a filtragem, os extratos foram diluídos em cinco concentrações (20, 40,60, 80 e 100\%). Além das concentrações dos extratos, as sementes foram embebidas em cinco concentrações de ácido giberélico, marca Pro Gibb ${ }^{\circledR}(200,400,600,800$ e $1000 \mathrm{mg} \mathrm{L}^{-1} \mathrm{GA}_{3}$ ). Como tratamento controle utilizouse água destilada. O delineamento experimental foi inteiramente casualizado, apresentando 16 tratamentos, contendo cinco repetições cada, totalizando 80 unidades experimentais, cada uma dez sementes (Tabela 1).

Para os testes de germinação utilizaram-se placas de Petri forradas com dois discos de papel germitest, previamente autoclavadas a $120^{\circ} \mathrm{C}$, por 30 minutos. Os discos foram umedecidos com $10 \mathrm{~mL}$ dos extratos, hormônio ou água destilada, de acordo com os tratamentos pré-estabelecidos. Posteriormente, as placas com as sementes foram levadas para BOD, sendo mantidas nestas condições por 45 dias, em 
Tabela 1 - Descrição dos tratamentos, de sementes de maracujazeiro embebidas nos extratos de bulbos e folhas de tiririca e ácido giberélico. Unioeste, Campus Marechal Cândido Rondon, PR. 2015.

Table 1 - Description of treatment of passion fruit seeds embedded in the bulb extracts and Cyperus leaves and gibberellic acid. Unioeste, Campus Marechal Cândido Rondon, PR. 2015.

\begin{tabular}{cl}
\hline Tratamentos & Descrição \\
\hline 1 & Controle (água destilada) \\
2 & Extrato de bulbos de tiririca $20 \%$ \\
3 & Extrato de bulbos de tiririca $40 \%$ \\
4 & Extrato de bulbos de tiririca $60 \%$ \\
5 & Extrato de bulbos de tiririca $80 \%$ \\
6 & Extrato de bulbos de tiririca $100 \%$ \\
7 & Extrato de folhas de tiririca $20 \%$ \\
8 & Extrato de folhas de tiririca $40 \%$ \\
9 & Extrato de folhas de tiririca $60 \%$ \\
10 & Extrato de folhas de tiririca $80 \%$ \\
11 & Extrato de folhas de tiririca $100 \%$ \\
12 & Ácido giberélico $200 \mathrm{mg} \mathrm{L}^{-1}$ \\
13 & Ácido giberélico $400 \mathrm{mg} \mathrm{L}^{-1}$ \\
14 & Ácido giberélico $600 \mathrm{mg} \mathrm{L}^{-1}$ \\
15 & Ácido giberélico $800 \mathrm{mg} \mathrm{L}^{-1}$ \\
16 & Ácido giberélico $1000 \mathrm{mg} \mathrm{L}^{-1}$ \\
\hline
\end{tabular}

temperatura constante de $25^{\circ} \mathrm{C}$.

Diariamente foram realizadas contagens do número de sementes germinadas, determinandose assim a percentagem de germinação, bem como o índice de velocidade de germinação (IVG), sendo esse calculado segundo fórmula descrita por MAGUIRE (1962). Foram consideradas germinadas as sementes que apresentaram $2 \mathrm{~mm}$ de protusão radicular. Os resultados obtidos foram submetidos à análise de variância, pelo programa estatístico Sisvar (FERREIRA 2011), e as médias discriminadas pelo teste Tukey, a 5\% de probabilidade de erro.

\section{RESULTADOS E DISCUSSÃO}

Na Tabela 2 verificam-se os resultados da percentagem de germinação de maracujá-amarelo, submetida à transformação arco seno raiz quadrada de $\mathrm{x} / 100$.

Conforme Tabela 2, verificaram-se diferenças significativas entre os tratamentos com ácido giberélico, que inibiram completamente a germinação de sementes de maracujá-amarelo, e a testemunha, que apresentou taxa de germinação de $86 \%$. O ácido giberélico pode apresentar comportamento distinto na germinação de sementes de espécies vegetais, em alguns casos atuando como estimulante, e em outros como inibidor. Este fitorregulador atua principalmente controlando o alongamento e divisão celular, diretamente ligado a germinação e a taxa de crescimento da planta.

Resultados antagônicos são observados em diferentes estudos sobre germinação de espécies frutíferas utilizando o ácido giberélico. Concentrações de ácido giberélico na embebição de sementes foram prejudiciais na germinação de nogueira-macadâmia (DALASTRA et al. 2010). Porém, a germinação de sementes de atemóia foi otimizada quando submetidas à imersão em ácido giberélico por 36 horas (OLIVEIRA et al. 2010).

$\mathrm{Na}$ Tabela 2 verificam-se os resultados dos tratamentos que continham extratos de folhas e bulbos de tiririca, não havendo diferença significativa entre os tratamentos, indicando assim que os extratos não estimularam nem inibiram a germinação de sementes de maracujá-amarelo. Observou-se que a maioria dos tratamentos com extrato de tiririca apresentou comportamento semelhante à testemunha, sendo que apenas as concentrações 40, 60 e $100 \%$ do extrato de bulbos de tiririca assemelharam-se aos tratamentos com ácido giberélico.

Altas concentrações de extrato aquoso de 
folhas de tiririca reduziram a percentagem de germinação de sementes de nabo, brócolis, couveflor e rabanete (ANDRADE et al. 2009). Os mesmos autores observaram uma redução no percentual de germinação de sementes de alface e tomate, independente da concentração utilizada do extrato, e redução no percentual de germinação de repolho, nas concentrações de extrato de 90 e 100\%. Em linhas gerais, a folha é o órgão da planta mais ativo metabolicamente, sendo razoável que esta apresente maior diversidade de aleloquímicos e maior efeito fitotóxico (RIBEIRO et al. 2009).

$\mathrm{Na}$ Tabela 3 verificam-se os resultados do IVG de sementes de maracujá-amarelo, submetidos à transformação arco seno raiz quadrada de x/100.

De acordo com a Tabela 3, observou-se que apenas os tratamentos com ácido giberélico e a testemunha apresentaram resultados significativamente diferentes entre si para o IVG, que foi menor nos tratamentos com ácido giberélico, sendo sua aplicação prejudicial à germinação de sementes de maracujá-amarelo. Alterações nas curvas de germinação e IVG calculados indicam, segundo LABOURIAU (1983), interferências nas reações metabólicas que culminam na germinação.

$\mathrm{O}$ umedecimento do substrato com soluções aquosas de ácido giberélico aumenta a velocidade de germinação e reduz o tempo médio de germinação de sementes de macela (BEZERRA et al. 2006). Observou-se incremento na velocidade de germinação de sementes de atemóia após imersão das mesmas em ácido giberélico (OLIVEIRA et al. 2010). Resultados contrastantes foram verificados por LUZ et al. (2008), sem influência dos tratamentos com ácido giberélico na germinação de sementes de palmeira-ráfia, não sendo recomendado sua aplicação para a cultura.

Todos os tratamentos com extrato de tiririca foram semelhantes entre si para o IVG, sendo que apenas os tratamentos nas concentrações de 40 e $60 \%$ do extrato de bulbos de tiririca foram semelhantes aos tratamentos com ácido giberélico. GUSMAN et al. (2012) verificaram que doses acima de 30\% de extrato aquoso de tiririca causaram diminuição no IVG, sendo que, essa diminuição aumenta conforme

Tabela 2 - Percentagem de germinação (\%) de maracujá-amarelo submetida a concentrações de extrato de tiririca e ácido giberélico. Unioeste, Campus Marechal Cândido Rondon, PR. 2015.

Table 2 - Germination percentage (\%) of yellow passion fruit submitted to Cyperus extract concentrations and gibberellic acid. Unioeste, Campus Marechal Cândido Rondon, PR. 2015.

\begin{tabular}{lcccccccc}
\hline Tratamentos & $\mathrm{T} 1$ & $\mathrm{~T} 2$ & $\mathrm{~T} 3$ & $\mathrm{~T} 4$ & $\mathrm{~T} 5$ & $\mathrm{~T} 6$ & $\mathrm{~T} 7$ & $\mathrm{~T} 8$ \\
\hline \% germinação & $86 \mathrm{a}$ & $52 \mathrm{ab}$ & $32 \mathrm{bc}$ & $32 \mathrm{bc}$ & $58 \mathrm{ab}$ & $40 \mathrm{bc}$ & $54 \mathrm{ab}$ & $76 \mathrm{ab}$ \\
\hline Tratamentos & $\mathrm{T} 9$ & $\mathrm{~T} 10$ & $\mathrm{~T} 11$ & $\mathrm{~T} 12$ & $\mathrm{~T} 13$ & $\mathrm{~T} 14$ & $\mathrm{~T} 15$ & $\mathrm{~T} 16$ \\
\hline \% germinação & $64 \mathrm{ab}$ & $60 \mathrm{ab}$ & $50 \mathrm{ab}$ & $0 \mathrm{c}$ & $0 \mathrm{c}$ & $0 \mathrm{c}$ & $0 \mathrm{c}$ & $0 \mathrm{c}$ \\
\hline CV $(\%)$ & & & & & 36,99 & & &
\end{tabular}

Médias seguidas pela mesma letra, na coluna, não diferem entre si pelo teste de Tukey, a 5\% de probabilidade de erro.

Tabela 3 - Índice de Velocidade de Germinação (IVG) em sementes de maracujá-amarelo submetidas a diferentes doses de extrato de tiririca e ácido giberélico. Unioeste, Campus Marechal Cândido Rondon, PR. 2015.

Table 3 - Germination speed index (IVG) in yellow passion fruit seeds under different sedge extract doses and gibberellic acid. Unioeste, Campus Marechal Cândido Rondon, PR. 2015.

\begin{tabular}{lcccccccc}
\hline Tratamentos & T1 & T2 & T3 & T4 & T5 & T6 & T7 & T8 \\
\hline IVG & $0,28 \mathrm{a}$ & $0,15 \mathrm{ab}$ & $0,08 \mathrm{bc}$ & $0,10 \mathrm{bc}$ & $0,19 \mathrm{ab}$ & $0,13 \mathrm{abc}$ & $0,16 \mathrm{ab}$ & $0,22 \mathrm{ab}$ \\
\hline Tratamentos & $\mathrm{T} 9$ & $\mathrm{~T} 10$ & $\mathrm{~T} 11$ & $\mathrm{~T} 12$ & $\mathrm{~T} 13$ & $\mathrm{~T} 14$ & T15 & T16 \\
\hline IVG & $0,19 \mathrm{ab}$ & $0,19 \mathrm{ab}$ & $0,16 \mathrm{ab}$ & $0 \mathrm{c}$ & $0 \mathrm{c}$ & $0 \mathrm{c}$ & $0 \mathrm{c}$ & $0 \mathrm{c}$ \\
\hline CV (\%) & & & \multicolumn{7}{c}{5,18} & & &
\end{tabular}

Médias seguidas pela mesma letra, na coluna, não diferem entre si pelo teste de Tukey, a 5\% de probabilidade de erro. 
o incremento na concentração do extrato em sementes de alface, tomate, repolho e rabanete.

Trabalhos futuros devem ser realizados com concentrações de ácido giberélico e extratos de tiririca, outras formas de embebição de sementes de maracujá-amarelo e avaliações na fase de crescimento/ desenvolvimento das plântulas.

\section{CONCLUSÕES}

Sementes de maracujá-amarelo submetidas às concentrações de ácido giberélico tiveram sua germinação inibida, não sendo recomendado na germinação da espécie.

Concentrações de extrato aquoso de folhas e bulbos de tiririca não influenciaram a germinação de sementes de maracujá-amarelo.

\section{REFERÊNCIAS}

ANDRADE HM et al. 2009. Potencial alelopático de Cyperus rotundus L. sobre espécies cultivadas. Ciênc. Agrotec. 33: 1984-1990. Edição especial.

BEZERRA AME et al. 2006. Efeito da pré-embebição e aplicação de ácido giberélico na germinação de sementes de macela. Rev. Bras. Sementes. 28: 185-190.

BRITO ICA \& SANTOS DR. 2012. Alelopatia de espécies arbóreas da caatinga na germinação e vigor de sementes de feijão Macacar. Rev. Verde Agroecologia Desenvolv. sustent. 7: 129-140.

CATUNDA MG et al. 2002. Efeitos de extrato aquoso de tiririca sobre a germinação de alface, pimentão e jiló e sobre a divisão celular na radícula de alface. Rev. Ceres. 49: 1-1. CREMONEZ FE et al. 2013. Principais plantas com potencial alelopático encontradas nos sistemas agrícolas brasileiros. Acta Iguaçu. 2: 70-88.

DALASTRA IM et al. 2010. Germinação de sementes de nogueira-macadâmia submetidas à incisão e imersão em ácido giberélico. Ciênc. Agrotec. 34: 641-645.

FERREIRA, DF. 2011. Sisvar: a computer statistical analysis system. Ciênc. Agrotec. 35: 1039-1042.

GUSMAN GS et al. 2011. Potencial alelopático de extratos aquosos de Bidens pilosa L., Cyperus rotundus L. e Euphorbia heterophylla L. Série Botânica. 66: 87-98.

GUSMAN GS et al. 2012. Alelopatia de espécies vegetais com importância farmacêutica para espécies cultivadas. Biotemas. 25: 37-48.

INSTITUTO BRASILEIRO DE GEOGRAFIA E ESTATÍSTICA. IBGE. 2012. Banco de dados agregados: SIDRA. Disponível em: <http://www.sidra.ibge.gov.br>. Acesso em: 22 mar. 2015.

LABOURIAU LFG 1983. A germinação das sementes. Washington: Departamento de Assuntos Científicos e Tecnológicos da Secretaria Geral da Organização dos
Estados Americanos. 174 p. (Série Biologia, 24).

LIMA CSM et al. 2009. Germinação de sementes e crescimento de maracujá em diferentes concentrações do ácido giberélico, tempos de imersão e condições experimentais. Revista Bras. Agroc. 15: 43-48.

LORENZI H. 2000. Plantas daninhas do Brasil: terrestres, aquáticas, parasitas e tóxicas. 3. ed. Nova Odessa: Instituto Plantarum, 608p.

LUZ PB et al. 2008. Germinação de sementes de palmeiraráfia: efeito de tratamentos pré-germinativos. Rev. Árvore. 32: 793-798.

MAGUIRE JD. 1962. Speeds of germination-aid selection and evaluation for seedling emergence and vigor. Crop Science. 2: 176-177.

RIBEIRO JPN et al. 2009. Efeitos alelopáticos de extratos aquosos de Crinum americanum L. Rev. Bras. Bot. 32: 183-188.

SABIÃO RR et al. 2011. Enraizamento de estacas de Passiflora nitida submetidas a diferentes concentrações de ácido indolbutírico (AIB). Rev. Bras. Frut. 33: 654-657.

SANTOS CAC et al. 2013. Germinação de sementes e vigor de plântulas de maracujazeiro amarelo submetidos à ação do ácido giberélico. Biosci. J. 29: 400-407.

OLIVEIRA MC et al. 2010. Germinação de sementes de atemóia (Annona cherimola Mill. x A. squamosa L.) cv 'Gefner' submetidas a tratamentos com ácido giberélico (GA3) e ethephon. Rev. Bras. Frut. 32: 544-554.

WAGNER JÚNIOR A et al. 2006. Influência do substrato na germinação e desenvolvimento inicial de plantas de maracujazeiro amarelo (Passiflora edulis sims f. flavicarpa deg). Ciênc. Agrotec. 30: 643-647. 